\title{
Evidence that Low Density Lipoprotein Is the Primary Cause of Atherosclerotic Cardiovascular Disease: A Bradford-Hill Approach
}

\author{
David S. Schade1 ${ }^{*}$, Deborah Helitzer ${ }^{2}$, Philip Eaton ${ }^{1}$ \\ ${ }^{1}$ Division of Endocrinology, Department of Internal Medicine, University of NM School of Medicine, Albuquerque, NM, USA \\ ${ }^{2}$ Family and Community Medicine, University of NM School of Medicine, Albuquerque, NM, USA \\ Email: *dschade@salud.unm.edu
}

How to cite this paper: Schade, D.S., Helitzer, D. and Eaton, P. (2017) Evidence that Low Density Lipoprotein Is the Primary Cause of Atherosclerotic Cardiovascular Disease: A Bradford-Hill Approach. World Journal of Cardiovascular Diseases, 7, 271-284.

https://doi.org/10.4236/wjcd.2017.79025

Received: April 14, 2017

Accepted: September 16, 2017

Published: September 19, 2017

Copyright $\odot 2017$ by authors and Scientific Research Publishing Inc. This work is licensed under the Creative Commons Attribution International License (CC BY 4.0).

http://creativecommons.org/licenses/by/4.0/

\begin{abstract}
Cardiovascular disease is the leading cause of death in the Westernized world. The costs in productive lives lost to individuals, families, and society are staggering. The epidemiology, pathogenesis, and preventative treatment are all clearly described. Why then, has this epidemic not been eradicated? One reason is the uncertainty about the primary cause of atherosclerotic cardiovascular disease. Low density lipoprotein (LDL) is a circulating lipid particle that deposits cholesterol into the arterial wall which subsequently evolves into an atherosclerotic plaque and a life-threatening arterial thrombosis. The reason that LDL is not universally accepted as the cause of atherosclerosis is that there are no randomized controlled trials (RCT's) providing this evidence. For ethical, financial, and scientific reasons, an RCT of sufficient duration to prove or disprove this hypothesis may never be initiated. We propose a unique approach to support the critical role of LDL in the pathogenesis of cardiovascular disease. Employing criteria based on those proposed by Sir Austin Bradford Hill, we describe the large body of scientific evidence supporting LDL as the primary cause of atherosclerosis. Sir Austin Bradford Hill was a British epidemiologist/statistician who lived in the $20^{\text {th }}$ century. He acknowledged that the cause of a disease could not always be established by a randomized clinical trial. Therefore, he outlined nine criteria (now known as the Bradford-Hill criteria) that should be met if an etiological factor was likely the cause of a disease. The data in this manuscript are organized according to these nine criteria. These data strongly suggest that LDL is the primary cause of atherosclerotic cardiovascular disease and that sufficient LDL reduction (i.e., to $<70 \mathrm{mg} / \mathrm{dl})(<1.81 \mathrm{mmol} / \mathrm{L})$ will lead to atherosclerotic cardiovascular
\end{abstract}


disease becoming a rare event.

\section{Keywords}

Low Density Lipoprotein

\section{Introduction}

The evidence-based understanding of the pathophysiology of coronary atherosclerosis has continued to accumulate since the studies of Watanabe, Niemen Pick like protein, the Tarahumara Indians and Brown and Goldsteins' LDL receptor hypothesis all elucidated key mechanisms in the consequences of elevated blood low density lipoprotein (LDL) cholesterol. However, it should be acknowledged that LDL (Figure 1) is not the only circulating atherogenic lipoprotein. Specifically, intermediate density lipoprotein and very low density lipoprotein, may all contribute cholesterol to the atherosclerotic plaque. These two cholesterol carriers are converted in the circulation to LDL by removal of lipoproteins and triglyceride [1]. Since the non-high-density lipoprotein cholesterol concentration indirectly includes all of these lipoprotein species, it may be a slightly better predictor of future cardiovascular events [2] [3]. However, since LDL cholesterol carries $80 \%$ of the circulating cholesterol under conditions of normal lipemia [4] and since LDL cholesterol is the measured lipoprotein for almost all randomized clinical trials, this article will focus on the essential role of LDL cholesterol in the pathogenesis of atherosclerosis.

Randomized clinical trials of stat in therapy have resulted in significant cardiovascular benefits which have been proportional to the reduction in LDL

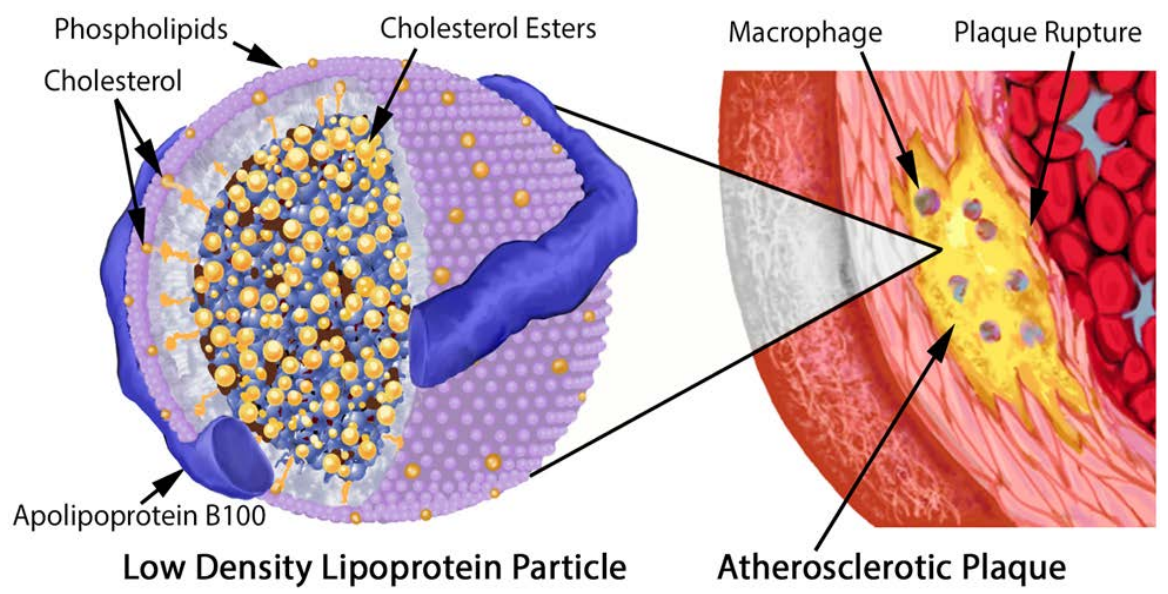

Figure 1. Structure of LDL cholesterol and its role in atherosclerosis. The major lipoprotein (apolipoprotein B-100) is responsible for LDL binding to cellular receptors. LDL particles are oxidized in the arterial wall, then taken up by tissue macrophages. The lipid laden macrophages coalesce into a fatty streak which then evolves into an atherosclerotic plaque. The plaque may rupture if the fibrous cap thins and fractures, causing a thrombosis and a heart attack. 


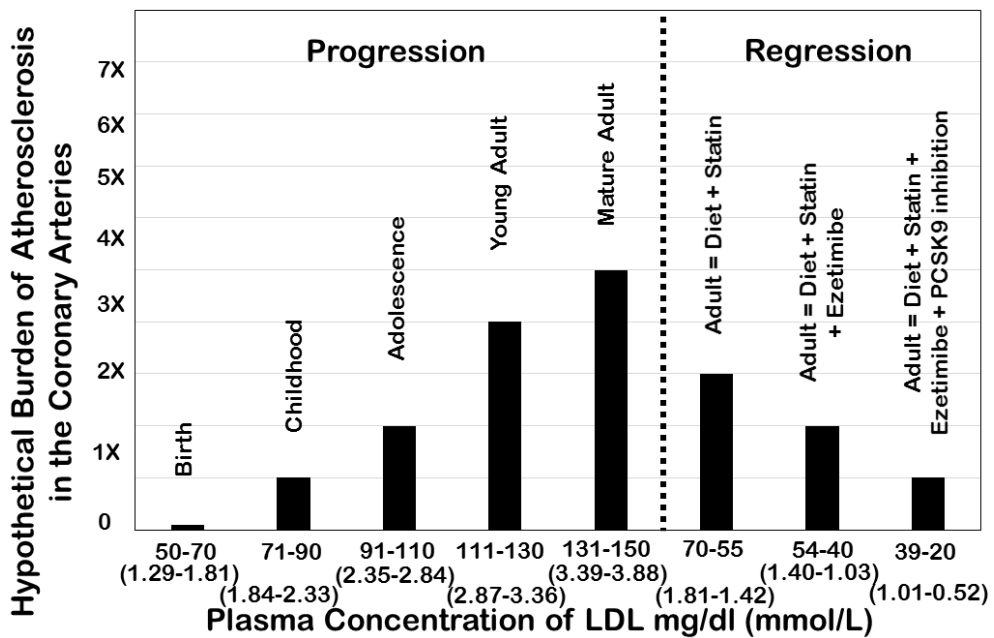

Figure 2. Progressive increases in LDL result in an increasing atherosclerotic burden. Since this burden is expressed as multiple atherosclerotic plaques, clinical cardiovascular events become manifested in the mature adult. If the adult subsequently reduces his/her LDL below $70 \mathrm{mg} / \mathrm{dl}(1.81 \mathrm{mmol} / \mathrm{L})$ via diet and/or medication, the atherosclerotic burden can be reduced and atherosclerosis can be reversed [6] [48].

cholesterol concentration [5]. The LDL concentration determines the increase or decrease in atherosclerotic burden (Figure 2) [6]. Furthermore, for optimal clinical outcomes, extensive genetic, pathophysiological, and experimental evidence support maintaining an LDL cholesterol concentration of $<50 \mathrm{mg} / \mathrm{dl}(1.3$ $\mathrm{mmol} / \mathrm{L}$ ). Based on these published data, significantly reducing the number one cause of death in the Western world would be expected [6]. However, this expectation has not materialized because of doubts that LDL is the primary cause of atherosclerosis. These doubts are based on the fact that an RCT of a causal role of LDL in atherosclerosis has not been reported. This scientific limitation exists because there is no available methodology that will only reduce the concentration of this lipoprotein without additional collateral confounding pharmacological effects. In addition, for reasons of ethics, finances, and scope (the necessity of testing all populations at risk), an RCT of sufficient duration and size to prove or disprove this LDL hypothesis may never be initiated. Therefore, an alternative approach to establishing a cause and effect scenario is required. To that end, organizing the evidence according to the "cause and effect" epidemiological criteria that Sir Bradford Hill proposed in 1965 provides a scientific platform to support LDL cholesterol's critical pathogenic role [7].

Sir Austin Bradford Hill was born in 1897 and had a long, distinguished career as a statistician and epidemiologist. He was knighted in 1961. Among many other accomplishments, he was instrumental in connecting smoking with lung cancer. He is best remembered for a Presidential address that he gave to the Royal Society of Medicine in 1965 in which he listed nine criteria that should be met to establish causality [7]. These criteria have since been applied to several areas, including connections between ultraviolet radiation and cancer, vitamin D and neonatal outcomes, alcohol and cardiovascular disease, and infections and the 
risk of stroke. Bradford Hill's nine criteria have been much debated in the medical literature, with both proponents and antagonists making valid arguments. To date, however, no other criteria have been published that provide the wide scope of conditions that may be used to address causality.

The paragraphs below paraphrase the nine Bradford-Hill Criteria intended to establish a "cause and effect" relationship between the concentration of LDL cholesterol and the presence of atherosclerotic cardiovascular disease. Although there are other contributing factors to atherosclerosis (usually termed risk factors), without a lipid core originating from LDL cholesterol, atherosclerotic plaques do not form nor rupture into an arterial lumen.

Strength and Association- "Cause and effect" may be suggested by statistical correlation between repeated events or experiments.

The physiological baseline for plasma LDL cholesterol is that concentration observed in the human newborn of 50 to $70 \mathrm{mg} / \mathrm{dl}(1.3$ to $1.81 \mathrm{mmol} / \mathrm{L})$ [8]. The effect of coronary atherosclerosis caused by the increase in blood concentration of LDL cholesterol above $70 \mathrm{mg} / \mathrm{dl}(1.81 \mathrm{mmol} / \mathrm{L})$ is recognized by "heart attacks" arising from acute coronary occlusion. The observed nadir of plasma LDL concentration in regression analysis of clinical trials of LDL lowering in both primary and secondary intervention has been demonstrated to approximate 70 $\mathrm{mg} / \mathrm{dl}(1.81 \mathrm{mmol} / \mathrm{L})$ with the projected extension down to $50 \mathrm{mg} / \mathrm{dl}(1.3$ $\mathrm{mmol} / \mathrm{L}$ ) to achieve minimal atherosclerotic events. In these primarily randomized controlled studies, the starting plasma LDL cholesterol concentrations were generally between 100 and $200 \mathrm{mg} / \mathrm{dl}(2.59$ and $5.18 \mathrm{mmol} / \mathrm{L})$, and with stat in exposure demonstrated a statistically significant regression, aligning with a nadir of $50 \mathrm{mg} / \mathrm{dl}(1.3 \mathrm{mmol} / \mathrm{L})$. This approach is the least invasive or lifestyle altering when medications (primarily statins and lifestyle interventions) have been used as the intervention arm, but surgical ileal bypass, diet trials, and bile acid sequestrants also have been employed as LDL cholesterol lowering procedures [9]. Vegetarians have improved cardiovascular risk factor profiles including lower LDL cholesterol. This is especially true of vegetarians who do not consume dairy products [10]. Not surprisingly, they have a reduction in cardiovascular events compared to non vegetarians [11]. These data all suggest that LDL cholesterol plays a pivotal role in the atherosclerotic process with the simultaneous reduction in both LDL cholesterol and the occurrence of cardiovascular events.

Plausibility-The apparent cause and effect must make sense in the light of current theories and results.

Early histological studies demonstrated that LDL cholesterol was present within atherosclerotic plaques, consistent (but not proof) with the causal role of LDL cholesterol in the formation of atheroma in man and animal models [12]. Much of this LDL cholesterol had been oxidized and subsequently taken up by macrophages forming a fatty streak in the arterial wall. Cytokines secreted by macrophages and arterial wall muscle cells incited an inflammatory response resulting in an atherosclerotic plaque. More recent investigations have shown 
that inflammatory white cells (primarily macrophages) not only secrete inflammatory cytokines but also are responsible for ingesting the oxidized LDL cholesterol prior to coalescing to form foam cells prior to becoming atherosclerotic plaques. Among the cytokines secreted by white blood cells are metalloproteinases which dissolve the plaques surface cap and permit exudation of cholesterolemicthrombotic material into the coronary vessel lumen [13]. This process initiates the formation of plateletmicro thrombi and blood clots with subsequent obstruction of the coronary artery. In addition to the concentration of LDL cholesterol, the size and density of the LDL particle have been shown to be important determinants of the atherogenicity of LDL cholesterol [14]. Small, dense LDL particles are the most atherogenic, probably because they rapidly pass through the arterial endothelium and are more rapidly oxidized than larger LDL cholesterol lipoproteins. Since macrophages have specific receptors for oxidized $\mathrm{LDL}$, this process is a necessary prerequisite for fatty streak formation. Small, dense LDL particles are characteristic of the hypertriglyceridemic state [15].

In 1985, Brown and Goldstein provided the molecular physiology for an LDL receptor on the surface of liver cells that play a determining role in removing LDL from the blood thereby reducing the concentration of plasma LDL cholesterol [16]. This discovery provided the mechanistic insight into the importance of the liver in determining the circulating LDL cholesterol concentration. The reduction of circulating LDL cholesterol by increasing the hepatic LDL cholesterol receptor (via several mechanisms) has been shown to result in a significant reduction in atherosclerotic events [17]. This direct relationship between the availability of LDL cholesterol and the severity of atherosclerosis provides a plausible cause and effect relationship.

Temporality-There is a time relationship between cause and effect in that the effect occurs after the cause.

Atherosclerosis is a progressive disease that develops over decades. Although cardiovascular events are uncommon before the age of 40 years, the presence of atherosclerotic plaques can be demonstrated years before, following prolonged exposure to elevated plasma LDL cholesterol. In the teenage years, early atherosclerotic plaques can be identified by both intravascular ultrasound and coronary artery calcium scanning [18]. In fact, the initial stages of atherosclerosis (fatty streak formation and the migration of macrophages into the arterial wall) can be observed in the human fetus [19]. This fact implies that the duration of atherosclerosis may begin at birth or during gestation for many individuals.

In all reported cases, the hypercholesterolemia precedes the atherosclerotic event. This fact is strikingly illustrated by the condition of homozygous familial hypercholesterolemia which is identifiable at birth by greatly elevated blood LDL cholesterol and genetic testing [20]. In this condition, there is a genetic defect either in the number and/or function of the LDL receptor or the structure and function of apolipoprotein B (the main receptor binding protein of LDL cholesterol) resulting in greatly reduced LDL removal from the circulation and severe hypercholesterolemia. External dermatological manifestations (e.g., tuberous 
xanthomas and xanthelasmas) and death from atherosclerotic events may occur by the age of 20 years [21].

Additional evidence of a time relationship between hypercholesterolemia and atherosclerosis can be observed in the general population. As this population ages, atherosclerosis continues to progress so that age is the number one predictor of cardiovascular disease [12]. Furthermore, the argument has been made that prolonged exposure to elevated levels of LDL cholesterol is as important (or more important) than short term exposure to hypercholesterolemia in causing atherosclerotic cardiovascular disease [22] [23]. These data underscore the positive temporal relationship between the duration of exposure to LDL cholesterol and the development of atherosclerosis. In other words, atherosclerosis never occurs before the hypercholesterolemia and thus the duration of the hypercholesterolemia is a critical determinant of the time when atherosclerosis first appears clinically.

Biological Gradient-In treatment, there might be expected to be a relationship between the dose given and the reaction of the patient. This may not be a simple linear relationship and may have minimum and maximum thresholds.

Clinical studies that result in lowering the LDL cholesterol by any means that work via increasing the concentration of the LDL cholesterol hepatic receptor, reduce the incidence of atherosclerosis [24]. In fact, the observation has been reported that for every mmol decline in LDL cholesterol concentration $(-38$ $\mathrm{mg} / \mathrm{dl})(-0.98 \mathrm{mmol} / \mathrm{L})$, the rate of atherosclerotic events decline $25 \%$ over the entire range of LDL cholesterol that has been studied [25]. This observation suggests that there is no threshold for the benefits of lowering LDL cholesterol in reducing cardiovascular events.

In all human populations, the concentration of LDL cholesterol varies over a wide range with a wide Gaussian distribution due to normal genetic variation. However, this range can be dramatically different depending upon the genetics and lifestyle of the population cited. For example, in agrarian populations such as the Tarahumara Indians in Mexico which have not embraced the Westernized lifestyle, cholesterol concentrations remain low $(\sim 70 \mathrm{mg} / \mathrm{dl})(\sim 1.81 \mathrm{mmol} / \mathrm{L})$ and atherosclerosis is minimal [26]. In contrast, in all Westernized societies in which traditionally relatively high fat, cholesterol diets are consumed, hypercholesterolemia is the norm (LDL cholesterol $>70 \mathrm{mg} / \mathrm{dl})(1.81 \mathrm{mmol} / \mathrm{L})$ (compared to LDL cholesterol concentrations at birth, i.e., 50 to $70 \mathrm{mg} / \mathrm{dl})(1.3$ to $1.81 \mathrm{mmol} / \mathrm{L})$ [8]. Furthermore, studies that result in volunteers obtaining LDL cholesterol concentrations below $70 \mathrm{mg} / \mathrm{dl}(1.81 \mathrm{mmol} / \mathrm{L})$ have shown additional benefit [17]. Thus, the lower the LDL cholesterol, the greater the reduction in atherosclerosis in a dose response fashion [6].

Consistency-To prove a concept is useful, it must give consistent results in a wide range of circumstances.

All pathological studies of atherosclerotic plaques have demonstrated a core of cholesterol esters and crystals surrounded by various inflammatory components 
including smooth muscle cells and fibrotic tissue [27]. Since LDL cholesterol contains $80 \%$ of the circulating cholesterol (most of the remaining cholesterol is located in high density lipoprotein), its oxidation and subsequent uptake by arterial macrophages is the primary culprit in the development of the atherosclerotic plaque [28]. Although there are several risk factors contributing to atherosclerosis (e.g., smoking, hypertension, obesity, diabetes, and a positive family history), excess circulating LDL cholesterol is necessary for atherosclerosis to develop. Support for this concept comes from three sources. First, histopathological studies examining coronary arteries following myocardial infarctions have always identified cholesterol in the ruptured plaque [29]. Second, clinical trial studies in which different statins have been compared or different doses of the same statins assessed for prevention of cardiovascular events have universally demonstrated that the regimen that produces the lowest concentration of LDL cholesterol results in the lowest cardiovascular event rate [30]. Third, atherosclerotic plaque reversal studies have repeatedly demonstrated that reversal of atherosclerotic plaques is first observed when the circulating concentration of LDL cholesterol goes below 65 to $70 \mathrm{mg} / \mathrm{dl}$ (1.68 to $1.81 \mathrm{mmol} / \mathrm{L}$ ) [31].

Alternatively, when circulating LDL cholesterol is elevated, increased cardiovascular risk rises in proportion to the LDL cholesterol elevation [6].The excess circulating cholesterol can be manifested by a wide range of pathophysiological conditions such as genetic deficiencies in the LDL cholesterol receptor, genetic overproduction of apolipoprotein B, excessive cholesterol absorption by the intestine, reduced hepatic binding of remnant lipoproteins, and reduced cholesterol removal by high density lipoprotein. Thus, the preeminent role of LDL cholesterol in supplying cholesterol to the arterial wall and its subsequent incorporation into atherosclerotic plaques can be demonstrated under innumerable circumstances and is consistently the target of aggressive medical therapy to reduce the consequences of atherosclerosis.

Specificity-A specific relationship is found if there is no other plausible explanation.

The composition of the atherosclerotic plaque is now well described. Its main components are cholesterol esters, inflammatory cells and their secreted cytokines, reactive smooth muscle cells, fibrous tissue, and a lesser multitude of atherosclerotic entities such as apolipoprotein (a), remnant apolipoproteins, and non-esterified fatty acids [4]. However, the initiation of the plaque is the fatty streak induced by the uptake of oxidized LDL by macrophages in the arterial vessel wall [13]. The LDL particles first migrate into the arterial wall through the endothelium, with the rate of migration being dependent on the concentration and size of the LDL particle [14]. The fatty streak macrophages then undergo a complex series of events resulting in activation of the smooth muscle cells in the vessel wall which migrate around the plaque and subsequently secrete various cytokines and chemo-attractants. Thus, there is a specific relationship between the inflamed endothelium, LDL cholesterol, and the migration of macrophages 
into the arterial wall, all leading to an atherosclerotic plaque [13]. These stepwise processes have been delineated through a series of histological, chemical, and post mortem studies of coronary arteries [13].

Evidence-A very strong proof of cause and effect comes from the results of experiments, where many significant variables are held stable to prevent them interfering with the results.

The recent explosion of gene technology has provided insight into the inherited factors that either reduce or exacerbate the risk of atherosclerosis. These "natural" experiments in which the genetic makeup of the individual provides a constant phenotype characterized by reduced (or increased) levels of LDL cholesterol correlating with a reduced (or increased) incidence of coronary atherosclerosis, respectively.

An example of genetic protection from atherosclerosis are individuals who are born with unusually low LDL cholesterol levels due to numerous genetic factors, e.g., the inability to complete the synthesis of apolipoprotein B by the liver [32]. These individuals have a very low incidence of cardiovascular disease. More recently, loss of function of the proprotein convertase subtilisin/kexin type 9 (PCSK9) protein has been described [33]. This protein is responsible for increasing the degradation of the hepatic LDL receptor resulting in decreased numbers of LDL cholesterol hepatic receptors. The consequence of this loss of PCSK9 protein function is the increased hepatic uptake of LDL and a reduction in its circulating levels. These individuals are protected from atherosclerosis. As might be anticipated, there are other individuals with an increased concentration of PCSK9 protein with consequent decreased quantity of hepatic LDL receptors who experience very high levels of circulating LDL and as a consequence accelerated atherosclerosis [34]. A further example are individuals in which the intestinal absorption of cholesterol is impaired due to decreased binding by the intestinal cholesterol receptor (i.e., the Nieman Pick-like protein receptor) [35]. This deficiency results in a reduction of free cholesterol in the liver and an up regulation of the hepatic LDL receptor. The consequence is a reduction in circulating LDL and a reduction in atherosclerosis [36]. This information has been used clinically to prescribe ezetimibe which partially blocks the intestinal cholesterol receptor and reduces atherosclerotic cardiovascular events [37]. All of these data provide strong evidence that the incidence of atherosclerosis is strongly related to the circulating concentration of LDL cholesterol, independent of the method that reduces its concentration. Thus, within the wide range of LDL concentrations observed in humans, the lower the LDL cholesterol level, the lower the incidence of atherosclerosis, i.e., the LDL principle [6].

Analogy-When something is suspected of causing an effect, then other factors similar or analogous to the supposed cause should also be considered and identified as a possible cause or otherwise eliminated from the investigation.

In non hypertriglyceridemic humans, LDLc contains approximately $80 \%$ of 
the cholesterol in circulating atherosclerotic lipoproteins [4]. However, in the context of other conditions (such as diabetes, hypertension, obesity, and tobacco exposure), other lipoprotein species and altered inflammatory constituents may contribute to the atherosclerotic process. For example, in patients with hypertriglyceridemia, the excess remnant cholesterol containing particles left over after hydrolysis of the triglyceride can be incorporated in the atherosclerotic plaque and incite inflammation [1]. Another example is apolipoprotein (a) which is genetically determined but altered by estrogens, nicotinic acid, and PCSK9 protein inhibitors [38]. This particle consists of an LDL particle covalently bound to another protein with homology with plasminogen. Because the apolipoprotein complex contains LDL, it is included in the measurement of LDL cholesterol. Elevated apolipoprotein (a) has been shown to be a risk factor for atherosclerosis in several population studies but the mechanism(s) of its atherosclerotic enhancement is not well defined [39]. Thus, although there are other risk factors for atherosclerosis, under normal circumstances in the majority of the U.S. population, LDL cholesterol is the primary mediator of this disease state.

Stabilization of the atherosclerotic plaque has been demonstrated to begin within one month of high dose statin therapy [40]. Furthermore, a meta-analysis of 20 reversal studies has shown that atherosclerosis reversal requires an LDL cholesterol below $70 \mathrm{mg} / \mathrm{dl}(1.81 \mathrm{mmol} / \mathrm{L})$ [30]. The presence of other cardiovascular risk factors may require this concentration to be significantly lower than $70 \mathrm{mg} / \mathrm{dl}(1.81 \mathrm{mmol} / \mathrm{L})$. The fact that the genesis of atherosclerosis depends upon excess LDL cholesterol moving into to the vessel wall and reversal occurs with the lowering of LDL below a specific concentration is strong evidence for a central role of LDL cholesterol as a causative factor for inducing atherosclerosis. The prime determinant of the circulating LDL cholesterol concentration is the activity of the hepatic LDL cholesterol receptor. These receptors are recycled on the hepatocyte surface approximately every 10 minutes [41]. Factors that increase LDL cholesterol receptor numbers reduce circulating LDL cholesterol and vice versa. In a meta-analysis of studies involving statin induced up regulation of the LDL cholesterol receptor expression, a reduction in LDL cholesterol concentration in the blood statistically accounted for the reduction in major cardiovascular events [17].

Finally, can LDL itself cause atherosclerotic plaques without the presence of confounding risk factors such as hypertension, diabetes, obesity, and smoking? The answer to this question is unequivocally yes. In the medical condition of familial homozygous hypercholesterolemia, the only defect is a loss of hepatic LDL receptor function with a result of greatly increased LDL concentration. These individuals have premature atherosclerosis and often require plasmapheresis to remove the LDL particles to prevent an early death from atherosclerosis [42]. This unique role of LDL stands out as the primary atherogenic lipid carrying circulating particle.

Coherence-If laboratory experiments in which variables are controlled 
and external everyday evidence are in alignment, then it is said that there is coherence.

Laboratory animals have characteristically low LDL levels and do not normally develop atherosclerosis. Therefore, to study atherosclerosis, either a genetic alteration increasing LDL production and/or reducing its disposal, or administration of ahypercholesterolemic diet is required. To this end, several animal models exist (including mice, rabbits, swine, and non-human primates) in which the process of atherosclerosis has been studied [43]. Wild-type mice are normally resistant to atherosclerosis, but lipoprotein receptor-deficient mice or apolipoprotein-deficient mice are commonly used to simulate human atherosclerosis [44]. In addition, one of the most frequently studied models is the Watanabe rabbit, which is characterized by a four amino acid defect in the hepatic LDL cholesterol receptor such that receptor binding to LDL cholesterol is reduced [45]. This animal model closely simulates the pathogenesis of human atherosclerosis and has been extensively studied by numerous techniques [46]. Although not completely identical to human atherosclerosis, these and other animal models have elucidated the importance of LDL in the formation of the fatty streak as well as the atherosclerotic plaque. All of these studies emphasize the importance of LDL cholesterol as the primary mediator of the atherosclerotic process. In fact, atherosclerosis cannot be generated without an elevation in LDL cholesterol.

\section{Conclusions}

The studies cited above, organized according to the nine Bradford-Hill epidemiological criteria, strongly support the importance of LDL cholesterol as the primary determinant of atherosclerosis. These extensive data complement the results of randomized controlled trials in humans demonstrating that the reduction of LDL cholesterol results in not only a reduction but a reversal of the atherosclerotic process. Clearly, LDL cholesterol is not the only contributor to the atherosclerotic process since several other factors may enhance its critical role in plaque formation and rupture. Thus, at any given level of LDL cholesterol, the progression of atherosclerosis may be increased by hypertension, smoking, diabetes, and obesity [47]. However, without the contribution of LDL cholesterol, clinically significant plaques do not form and atherosclerosis does not occur.

Knowledge gained in the last decade has permitted an extensive understanding of the role of LDL cholesterol in the pathogenesis of atherosclerosis. Detailed sequences have now been elucidated from the initial translocation of LDL cholesterol into the coronary artery wall to its subsequent oxidation, formation of the fatty streak, and ultimate rupture of the atherosclerotic plaque.

New therapies addressing the role of LDL cholesterol in atherogenesis have resulted in new therapeutic approaches (e.g., PCSK9 protein inhibitors and intestinal cholesterol receptor blockers) that may greatly reduce the incidence of heart attacks and strokes. Targeting specific levels of LDL cholesterol and identi- 
fication of concurrent risk factors provide the physician and patient with specific therapeutic goals that can determine the intensity and type of medical intervention. With this epidemiologic understanding of the cause and effect of atherosclerosis, the path to eradication of this number one cause of death can be realized.

\section{Acknowledgements}

Figure 1 is the art work of Christina Klauber, Albuquerque, New Mexico.

\section{Conflict of Interest}

The authors have no conflict of interest related to this manuscript.

\section{References}

[1] Castelli, W.P. (1986) The Triglyceride Issue: A View from Framingham. American Heart Journal, 112, 432-437. https://doi.org/10.1016/0002-8703(86)90296-6

[2] Farwell, W.R., Sesso, H.D., Buring, J.E. and Gaziano, J.M. (2005) Non-High-Density Lipoprotein Cholesterol versus Low-Density Lipoprotein Cholesterol as a Risk Factor for a First Nonfatal Myocardial Infarction. American Journal of Cardiology, 96, 1129-1134. https://doi.org/10.1016/j.amjcard.2005.06.044

[3] Grundy, S.M. (2002) Low-Density Lipoprotein, Non-High-Density Lipoprotein, and Apolipoprotein B as Targets of Lipid-Lowering Therapy. Circulation, 106, 2526-2529. https://doi.org/10.1161/01.CIR.0000038419.53000.D6

[4] Cohen, D.E. (2009) Lipoprotein Metabolism and Cholesterol Balance. The Liver: Biology and Pathobiology.

[5] Raymond, C., Cho, L., Rocco, M. and Hazen, S.L. (2014) New Cholesterol Guidelines: Worth the Wait? Cleveland Clinic Journal of Medicine, 81, 11-19. https://doi.org/10.3949/ccjm.81a.13161

[6] Schade, D.S., Cavanaugh, B., Ramo, B. and Eaton, R.P. (2016) The Application of the LDL Principle. World Journal of Cardiovascular Diseases, 6, 109-125. https://doi.org/10.4236/wjcd.2016.65012

[7] Hill, A.B. (1965) The Environment and Disease: Association or Causation? Proceedings of the Royal Society of Medicine, 58, 295-300.

[8] O’Keefe Jr., J.H. (2004) Optimal Low-Density Lipoprotein Is 50 to $70 \mathrm{mg} / \mathrm{dl}$ : Lower Is Better and Physiologically Normal. Journal of the American College of Cardiology, 43, 2142-2146. https://doi.org/10.1016/j.jacc.2004.03.046

[9] Silverman, M.G., Ference, B.A., Im, K., Wiviott, S.D., Giugliano, R.P. and Grundy, S.M. (2016) Association between Lowering LDL-C and Cardiovascular Risk Reduction among Different Therapeutic Interventions: A Systematic Review and Meta-Analysis. JAMA, 316, 1289-1297. https://doi.org/10.1001/jama.2016.13985

[10] Orlich, M.J., Singh, P.N., Sabaté, J., Jaceldo-Siegl, K., Fan, J., Knutsen, S., et al. (2013) Vegetarian Dietary Patterns and Mortality in Adventist Health Study 2. JAMA Internal Medicine, 173, 1230-1238. https://doi.org/10.1001/jamainternmed.2013.6473

[11] Key, T.J., Fraser, G.E., Thorogood, M., Appleby, P.N., Beral, V., Reeves, G., et al. (1999) Mortality in Vegetarians and Nonvegetarians: Detailed Findings from a Collaborative Analysis of 5 Prospective Studies. The American Journal of Clinical Nutrition, 70, 516S-524S. 
[12] Stary, H.C. (1989) Evolution and Progression of Atherosclerotic Lesions in Coronary Arteries of Children and Young Adults. Arteriosclerosis, Supplement I9, I19-I32.

[13] Libby, P. (2002) Atherosclerosis: The New View. Scientific American, 286, 46-55. https://doi.org/10.1038/scientificamerican0502-46

[14] El Harchaoui, K., van der Steeg, W.A., Stroes, E.S., Kuivenhoven, J.A., Otvos, J.D., Wareham, N.J., et al. (2007) Value of Low-Density Lipoprotein Particle Number and Size as Predictors of Coronary Artery Disease in Apparently Healthy Men and Women: The EPIC-Norfolk Prospective Population Study. Journal of the American College of Cardiology, 49, 547-553.

[15] Dayspring, T., Dall, T. and Abuhajir, M. (2010) Moving beyond LDL-C: Incorporating Lipoprotein Particle Numbers and Geometric Parameters to Improve Clinical Outcomes. Research Reports in Clinical Cardiology, 1, 1-10. https://doi.org/10.2147/RRCC.S14825

[16] Goldstein, J.L. and Brown, M.S. (2009) History of Discovery: The LDL Receptor. Arteriosclerosis, Thrombosis, and Vascular Biology, 29, 431-438. https://doi.org/10.1161/ATVBAHA.108.179564

[17] Baigent, C., Keech, A., Kearney, P.M., Blackwell, L., Buck, G., Pollicino, C., et al. (2005) Efficacy and Safety of Cholesterol-Lowering Treatment: Prospective Meta-Analysis of Data from 90,056 Participants in 14 Randomised Trials of Statins. The Lancet, 366, 1267-1278.

[18] Bacha, F., Edmundowicz, D., Sutton-Tyrell, K., Lee, S., Fjayli, H. and Arslanian, S.A. (2014) Coronary Artery Calcification in Obese Youth: What Are the Phenotypic and Metabolic Determinants? Diabetes Care, 37, 2632-2639.

https://doi.org/10.2337/dc14-0193

[19] Napoli, C., D’Armiento, F.P., Mancini, F.P., Postiglione, A., Witztum, J.L., Palumbo, G., et al. (1997) Fatty Streak Formation Occurs in Human Fetal Aortas and Is Greatly Enhanced by Maternal Hypercholesterolemia: Intimal Accumulation of Low Density Lipoprotein and Its Oxidation Precede Monocyte Recruitment into Early Atherosclerotic Lesions. The Journal of Clinical Investigation, 100, 2680-2690. https://doi.org/10.1172/JCI119813

[20] Wald, D.S., Bestwick, J.P., Morris, J.K., Whyte, K., Jenkins, L. and Wald, N.J. (2016) Child-Parent Familial Hypercholesterolemia Screening in Primary Care. The New England Journal of Medicine, 375, 1628-1637. https://doi.org/10.1056/NEJMoa1602777

[21] Rader, D.J., Cohen, J. and Hobbs, H.H. (2003) Monogenic Hypercholesterolemia: New Insights in Pathogenesis and Treatment. The Journal of Clinical Investigation, 111, 1795-1803. https://doi.org/10.1172/JCI200318925

[22] Brown, M.S. and Goldstein, J.L. (2006) Lowering LDL-Not Only How Low, but How Long? Science, 311, 1721-1723. https://doi.org/10.1126/science.1125884

[23] Leening, M.J.G., Berry, J.D. and Allen, N.B. (2016) Lifetime Perspectives on Primary Prevention of Atherosclerotic Cardiovascular Disease. JAMA, 315, 1449-1450. https://doi.org/10.1001/jama.2016.1654

[24] Sattar, N., Preiss, D., Murray, H.M., Welsh, P., Buckley, B.M., de Craen, A.J.M., et al. (2010) Statins and Risk of Incident Diabetes: A Collaborative Meta-Analysis of Randomized Statin Trials. The Lancet, 375, 735-742.

[25] Cholesterol Treatment Trialists' (CTT) Collaboration (2010) Efficacy and Safety of More Intensive Lowering of LDL Cholesterol: A Meta-Analysis of Data from 170,000 Participants in 26 Randomised Trials. The Lancet, 376, 1670-1681. 
[26] Connor, W.E., Cerqueira, M.T., Connor, R.W., Wallace, R.B., Malinow, M.R. and Casdorph, H.R. (1978) The Plasma Lipids, Lipoproteins, and Diet of the Tarahumaraindians of Mexico. The American Journal of Clinical Nutrition, 7, 1131-1142.

[27] Libby, P. and Theroux, P. (2005) Pathophysiology of Coronary Artery Disease. Circulation, 111, 3481-3488. https://doi.org/10.1161/CIRCULATIONAHA.105.537878

[28] Shaikh, M., Wootton, R., Nordestgaard, B.G., Baskerville, P., Lumley, J.S., La Ville, A.E., et al. (1991) Quantitative Studies of Transfer in Vivo of Low Density, Sf 12-60, and Sf 60-400 Lipoproteins between Plasma and Arterial Intima in Humans. Arteriosclerosis and Thrombosis, 11, 569-577. https://doi.org/10.1161/01.ATV.11.3.569

[29] Davies, M.J., Richardson, P.D., Woolf, N., Katz, D.R. and Mann, J. (1993) Risk of Thrombosis in Human Atherosclerotic Plaques: Role of Extracellular Lipid, Macrophage, and Smooth Muscle Cell Content. British Heart Journal, 69, 377-381. https://doi.org/10.1136/hrt.69.5.377

[30] Zhou, Z., Rahme, E. and Pilote, L. (2006) Are Statins Created Equal? Evidence from Randomized Trials of Pravastatin, Simvastatin, and Atorvastatin for Cardiovascular Disease Prevention. American Heart Journal, 151, 273-281.

[31] Gao, W.-Q., Feng, Q.-Z., Li, Y.-F., Li, Y.-X., Huang, Y., Chen, Y.-M., et al. (2014) Systematic Study of the Effects of Lowering Low-Density Lipoprotein-Cholesterol on Regression of Coronary Atherosclerotic Plaques using Intravascular Ultrasound. BMC Cardiovascular Disorders, 14, 60-78. https://doi.org/10.1186/1471-2261-14-60

[32] Zamel, R., Khan, R., Pollex, R.L. and Hegele, R.A. (2008) Abetalipoproteinemia: Two Case Reports and Literature Review. Orphanet Journal of Rare Diseases, 3, 19. https://doi.org/10.1186/1750-1172-3-19

[33] Cohen, J.C., Boerwinkle, E., Mosley, T.H. and Hobbs, H.H. (2006) Sequence Variations in PCSK9, Low LDL, and Protection against Coronary Heart Disease. The New England Journal of Medicine, 354, 1264-1272. https://doi.org/10.1056/NEJMoa054013

[34] Abifadel, M., Varret, M., Rabès, J.P., Allard, D., Ouguerram, K., Devillers, M., et al. (2003) Mutations in PCSK9 Cause Autosomal Dominant Hypercholesterolemia. Nature Genetics, 34, 154-156. https://doi.org/10.1038/ng1161

[35] Altmann, S.W., Davis, H.R., Zhu, L.J., Yao, X., Hoos, L.M., Tetzloff, G., et al. (2004) Niemann-Pick C1 Like 1 Protein Is Critical for Intestinal Cholesterol Absorption. Science, 303, 1201-1204. https://doi.org/10.1126/science.1093131

[36] Lauridsen, B.K., Stender, S., Frikke-Schmidt, R., Nordestgaard, B.G. and Tybjærg-Hansen, A. (2015) Genetic Variation in the Cholesterol Transporter NPC1L1, Ischaemic Vascular Disease, and Gallstone Disease. European Heart Journal, 36, 1601-1608. https://doi.org/10.1093/eurheartj/ehv108

[37] Cannon, C.P., Blazing, M.A., Giugliano, R.P., McCagg, A., White, J.A. and Theroux, P. (2015) Ezetimibe Added to Statin Therapy after Acute Coronary Syndromes. The New England Journal of Medicine, 372, 2387-2397. https://doi.org/10.1056/NEJMoa1410489

[38] Nordestgaard, B.G., Chapman, M.J., Ray, K., Borén, J., Andreotti, F., Watts, G.F., et al. (2010) Lipoprotein (a) as a Cardiovascular Risk Factor: Current Status. European Heart Journal, 31, 2844-2853. https://doi.org/10.1093/eurheartj/ehq386

[39] Santos, R.D. (2014) Lipoprotein (a) and Cardiovascular Disease in Heterozygous Familial Hypercholesterolemia: Should We Also Blame the LDL Receptor? Journal of the American College of Cardiology, 63, 1990-1991.

[40] Nakamura, T., Obata, J.E., Kitta, Y., Kobayashi, T., Fujioka, D., Saito, Y., et al. 
(2008) Rapid Stabilization of Vulnerable Carotid Plaque within 1 Month of Pitavastatin Treatment in Patients with Acute Coronary Syndrome. Journal of Cardiovascular Pharmacology, 51, 365-371. https://doi.org/10.1097/FJC.0b013e318165dcad

[41] Brown, M.S., Anderson, R.G. and Goldstein, J.L. (1983) Recycling Receptors: The Round-Trip Itinerary of Migrant Membrane Proteins. Cell, 32, 663-667.

[42] Raal, F.J., Pilcher, G.J., Panz, V.R., van Deventer, H.E., Brice, B.C., Blom, D.J., et al. (2011) Reduction in Mortality in Subjects with Homozygous Familial Hypercholesterolemia Associated with Advances in Lipid-Lowering Therapy. Circulation, 124, 2202-2207. https://doi.org/10.1161/CIRCULATIONAHA.111.042523

[43] Kapourchali, F.R., Surendiran, G., Chen, L., Uitz, E., Bahadori, B. and Moghadasian, M.H. (2014) Animal Models of Atherosclerosis. World Journal of Clinical Cases, 2, 126-132. https://doi.org/10.12998/wjcc.v2.i5.126

[44] Zaragoza, C., Gomez-Guerrero, C., Martin-Ventura, J.L., Blanco-Colio, L., Lavin, B., Mallavia, B., et al. (2011) Animal Models of Cardiovascular Diseases. Journal of Biomedicine and Biotechnology, 2011, Article ID: 497841. https://doi.org/10.1155/2011/497841

[45] Aliev, G. and Burnstock, G. (1998) Watanabe Rabbits with Heritable Hypercholesterolaemia: A Model of Atherosclerosis. Histology and Histopathology, 3, 797-817.

[46] Havel, R.J., Yarnada, N. and Shames, D.M. (1989) Watanabe Heritable Hyperlipidemic Rabbit: Animal Model for Familial Hypercholesterolemia. Arteriosclerosis, Supplement I9, 33-38.

[47] Greenland, P., Knoll, M.D., Stamler, J., Neaton, J.D., Dyer, A.R., Garside, D.B. and Wilson, P.W. (2003) Major Risk Factors as Antecedents of Fatal and Nonfatal Coronary Heart Disease Events. JAMA, 290, 891-897. https://doi.org/10.1001/jama.290.7.891

[48] Keraliya, A. and Blankstein, R. (2017) Regression of Coronary Atherosclerosis with Medical Therapy. NEJM, 376, 1370. https://doi.org/10.1056/NEJMicm1609054

\section{Scientific Research Publishing}

Submit or recommend next manuscript to SCIRP and we will provide best service for you:

Accepting pre-submission inquiries through Email, Facebook, LinkedIn, Twitter, etc. A wide selection of journals (inclusive of 9 subjects, more than 200 journals)

Providing 24-hour high-quality service

User-friendly online submission system

Fair and swift peer-review system

Efficient typesetting and proofreading procedure

Display of the result of downloads and visits, as well as the number of cited articles

Maximum dissemination of your research work

Submit your manuscript at: http://papersubmission.scirp.org/

Or contact wjcd@scirp.org 